\section{Discussion}

The recording of infant feeding patterns in the previous study, which included a dietary diary, was considered to be reliable. ${ }^{1}$ Eczema in the first year was also carefully defined and clinical assessment made by one doctor. In the follow up there was no reason to think that biases had arisen due, for example, to differential recall of asthma or eczema between 1 and 5 years of age by parents of children who received breast or bottle feeds in the first 4 weeks. The high response rate made it unlikely that biases could be the result of differential drop out rates.

No evidence was found for an association between type of feeding and development of asthma in the first 5 years. There is, however, a significant association between family history of atopy and risk of the child developing asthma by the age of 5 .

Studies of the aetiology of eczema tend to lack precision in the definition of eczema and accurate recording of the infant's diet. It is worrying that in this motivated and cooperative group of parents with a low drop out rate, recall at five years of eczema during the first year was relatively poor, even though the eczema was diagnosed and discussed with them by a doctor whom they saw regularly. This must have implications for studies relying exclusively on parental recall for evidence of eczema in infancy.

\section{Reference \\ 1 Moore WJ, Midwinter RE, Morris AF, Colley JRT, Soothill JF. Infant feeding and subsequent risk of atopic eczema. Arch Dis Child 1985;60:722-6.}

Correspondence to Dr R E Midwinter, Department of Epidemiology and Community Medicine, University of Bristol, Canynge Hall, Whiteladies Road, Bristol BS8 2PR.

Received 22 April 1987

\title{
Type $\mathrm{V}$ hyperlipoproteinaemia in neonates
}

\section{G N THOMPSON, A J KNIGHT, I HAMILTON CRAIG, AND J L BRESSON}

Department of Chemical Pathology, Adelaide Children's Hospital, North Adelaide, South Australia, and Paediatric Department, Necker Hospital for Sick Children, Paris, France

SUMMARY A boy investigated for neonatal jaundice was noted to have lipaemic serum and was subsequently shown to have type $\mathrm{V}$ hyperlipoproteinaemia. Dietary treatment was maintained for five years and he followed a typical clinical course. Circumstantial evidence suggested an autosomal recessive inheritance pattern.

Type V hyperlipoproteinaemia is rare in childhood and has not to our knowledge been described in a neonate. It is often difficult to distinguish between type I and type V hyperlipoproteinaemia, and differentiation usually relies on measuring plasma post-heparin lipoprotein lipase (PHLPL) activity which is deficient in type I hyperlipoproteinaemia and usually normal in type V. ${ }^{1}$ Until 1974 there was no accurate method of measuring plasma postheparin lipoprotein lipase. Since then three children have been reported with definite type $V$ hyperlipoproteinaemia but normal PHLPL activity, ${ }^{2-3}$ and there have been several descriptions of children with features suggesting type $\mathrm{V}$ hyperlipoproteinaemia ${ }^{4-6}$ The youngest reported was $2 \frac{1}{2}$ years old. ${ }^{4}$

\section{Case report}

A 5 year old boy who had been investigated for neonatal jaundice was found to have lactescent serum when 6 days old. Xanthelasma and eruptive xanthomata (buttocks) subsequently developed. The liver and spleen were not enlarged. Breast feeding was stopped and a feed containing a medium chain triglyceride formula (Pregestimil) was begun. The first plasma lipid profile was done when he was 2 months old, when a low fat diet started (table 1). The subsequent clinical course was uncomplicated and at 2 years of age, he began a normal diet. A brief recurrence of eruptive xanthomata, however, necessitated a return to restricted long chain triglyceride feeding.

The boy migrated to Australia with his family. When he was 2 years and 7 months old he developed acute pancreatitis. The parents, who controlled his diet carefully, reported no dietary indiscretion before the episode. Fasting serum lipid concentrations subsequently remained under control (table 1). Triglyceride concentrations, although never within the normal range, did not exceed $6.4 \mathrm{mmol} / \mathrm{l}$. High density lipoprotein cholesterol (mean 0.41 
Table 1 Fasting plasma lipid profile

\begin{tabular}{|c|c|c|c|c|c|c|c|c|}
\hline & \multicolumn{8}{|c|}{ Age (years) } \\
\hline & $0 \cdot 2^{*}$ & $0 \cdot 5$ & $l$ & 2 & $2 \cdot 7+$ & 4 & 5 & Normal range \\
\hline \multicolumn{9}{|c|}{ Plasma lipids $(\mathrm{mmol} / \mathrm{l})$ : } \\
\hline Triglyceride & $18 \cdot 4$ & $7 \cdot 7$ & 12 & $11 \cdot 4$ & $45 \cdot 1$ & $3 \cdot 1$ & 4.9 & $(0 \cdot 1-1 \cdot 6$ \\
\hline Total cholesterol & $3 \cdot 8$ & $1 \cdot 0$ & $1 \cdot 0$ & $2 \cdot 25$ & $10 \cdot 1$ & $2 \cdot 1$ & $4 \cdot 2$ & $3 \cdot 6-6 \cdot 2$ \\
\hline \multicolumn{9}{|c|}{ Lipoprotein electrophoretic pattern $(\%)$ : } \\
\hline Alpha & 7 & 10 & 15 & 6 & 14 & 5 & 6 & $35 \nmid$ \\
\hline Pre-Beta & 71 & 29 & 35 & 30 & \multirow[t]{2}{*}{$76^{9}$} & \multirow[t]{2}{*}{$82^{\pi}$} & 55 & $15 \ddagger$ \\
\hline Beta & 13 & 24 & 30 & 40 & & & 24 & $50 \div$ \\
\hline Chylomicrons & 9 & 37 & 20 & 24 & 10 & 13 & 15 & $0_{+}^{+}$ \\
\hline
\end{tabular}

*Just before start of fat restricted diet: †after pancreatitis; łupper limits of normal; "peaks not resolved.

$\mathrm{mmol} / \mathrm{l}$, range $0 \cdot 22-0 \cdot 57: \mathrm{n}=11$ measurements; normal range $0 \cdot 80-2 \cdot 20)$, low density lipoprotein cholesterol (mean $0.38 \mathrm{mmol} / \mathrm{l}$, range $0.03-1 \cdot 76$; $\mathrm{n}=8$ measurements; normal range $1 \cdot 30-4 \cdot 50$ ), and total cholesterol (Table 1) were usually below the normal range as is characteristic of treated type $\mathrm{V}$ hyperlipoproteinaemia. ${ }^{1}$ Lipoprotein electrophoretograms usually showed a type $\mathrm{V}$ pattern although occasional type IV patterns were noted.

Table 2 summarises his current diet. He remained well after his episode of pancreatitis apart from two brief recurrences of eruptive xanthomata on recent holidays. Serum lipoprotein concentrations were not measured during these episodes, but an increase in refined carbohydrate intake preceded each one. Growth has been normal and soft tissue swelling, as described by Deckelbaum et al, has not been noted. ${ }^{4}$
The boy is the youngest of three children; his parents, who are first cousins, and the siblings had normal serum lipid concentrations. Two paternal great uncles had hyperlipidaemia discovered late in adult life but further details of their diagnoses are not known.

Plasma post-heparin lipoprotein lipase activity at the age of 5 was normal, free fatty acid release from a synthetic triolein emulsion in low salt medium being $7 \cdot 14 \mu \mathrm{mol} / \mathrm{ml} /$ hour and in high salt medium $11.76 \mu \mathrm{mol} / \mathrm{ml} /$ hour compared with adult control values of 6.77 and 8.27 , respectively: plasma was collected 10 minutes after intravenous injection of heparin $10 \mathrm{U} / \mathrm{kg}^{7}$ Serum apolipoprotein C-II, C-III1, and C-III2 concentrations determined by polyacrylamide gel electrophoresis of very low density lipoprotein apolipoproteins in $8 \mathrm{M}$ urea were

Table 2 Diet* $\mathrm{g} / \mathrm{kg} / 24$ hours (\% total MJ intake) (figures in parentheses are numbers per cent)

\begin{tabular}{|c|c|c|c|c|c|c|c|}
\hline & \multicolumn{7}{|c|}{ Age (years) } \\
\hline & $0 \cdot 2$ & 0.5 & 1 & 2 & $2 \cdot 7$ & 4 & 5 \\
\hline \multicolumn{8}{|l|}{ Carbohydrate: } \\
\hline Total & $10(38)$ & $17 \cdot 4(64)$ & $17 \cdot 5(64)$ & $12(50)$ & NR & $13 \cdot 3(69)$ & $13.7(70)$ \\
\hline Refined & NR & $12 \cdot 1(44)$ & $7.9(29)$ & $4.8(20)$ & & 0 & 0 \\
\hline Unrefined & NR & $5 \cdot 2(19)$ & $9 \cdot 6(35)$ & $7 \cdot 2(30)$ & & $13 \cdot 3(69)$ & $13 \cdot 7(70)$ \\
\hline \multicolumn{8}{|l|}{ Fat: } \\
\hline Total & $6(51)$ & $2 \cdot 8(23)$ & $2 \cdot 2(18)$ & $3(28)$ & NR & $1 \cdot 1(13)$ & $1 \cdot 5(17)$ \\
\hline MCT & 0 & $1 \cdot 6(13)$ & 0 & 0 & 0 & 0 & $0 \cdot 4(4)$ \\
\hline LCT & $6(51)$ & $1 \cdot 2(10)$ & $2 \cdot 2(18)$ & $3(28)$ & & $1 \cdot 1(13)$ & $1 \cdot 1(14)$ \\
\hline Polyunsaturated & $0.6(5)$ & $0 \cdot 6(5)$ & $1 \cdot 2(10)$ & $0.4(4)$ & & NR & $0 \cdot 2(2)$ \\
\hline \multicolumn{8}{|c|}{ Total caloric intake ( $\mathrm{MJ} / \mathrm{kg} / 24$ hours) } \\
\hline & 25 & 26 & 26 & 23 & NR & 18 & 19 \\
\hline \multicolumn{8}{|l|}{ Clinical course: } \\
\hline Eruptive xanthomata & Yes & & & Yes & & & Yes \\
\hline Pancreatitis & & & & & Yes & & \\
\hline
\end{tabular}

${ }^{*}$ Calculated from three day diet diary except at $0 \cdot 2$ (established from recall diet); $N R=$ not recorded 
normal, as were serum immunoglobulin and uric acid concentrations, serum liver function tests, and glucose tolerance test showed no abnormalitites. Plasma vitamin A and E, and serum essential fatty acid concentrations have been measured yearly and have remained normal.

\section{Discussion}

The patient's clinical features are typical of both types I and V hyperlipoproteinaemia. The plasma lipid profile at 2 months of age strongly suggested the diagnosis of type $\mathrm{V}$ hyperlipoproteinaemia but did not exclude type I, which is a disorder seen more commonly in neonates. Familial apolipoprotein C-II deficiency is recessively inherited and may result in clinical and lipid profiles similar to those of type V hyperlipoproteinaemia. Normal PHLPL activity and apolipoprotein gel electrophoresis excluded these alternative diagnoses.

Familial type $\mathrm{V}$ hyperlipoproteinaemia is probably an expression of several different genotypes. ${ }^{2}$ Autosomal dominant inheritance had been well defined in some pedigrees but in other familial cases the inheritance pattern is not clear. ${ }^{15}$ Greenberg $e t$ $a l^{6}$ described a patient who was the child of a marriage of first cousins; the parents phenotypes were unfortunately not documented. Kwiterovich $e t$ $a l^{2}$ suggested autosomal recessive inheritance with variable expression of heterozygosity as a possible explanation for some pedigrees. No obligate heterozygotes had manifest type $\mathrm{V}$ hyperlipoproteinaemia in the pedigree described here; neonatal onset accompanied by negative but consanguineous family history suggests an autosomal recessive inheritance pattern.

The pathogenesis of type $\mathrm{V}$ hyperlipoproteinaemia has not been adequately explained, although a defect in clearance of very low density lipoprotein cholesterol has been proposed as the primary abnormality. ${ }^{1}$ Because of early onset and presumed autosomal recessive inheritance, this boy's primary defect probably differs from those of reported cases of type $\mathrm{V}$ hyperlipoproteinaemia and suggests aetiological heterogeneity of the disorder. ${ }^{\prime}$

For treatment of type $\mathrm{V}$ hyperlipoproteinaemia moderate dietary restriction (335 MJ in 24 hours for adults), restriction of regular fat $(25-30 \%$ of $\mathrm{MJ})$, moderate restriction of total carbohydrate $(40-50 \%$ of $\mathrm{MJ}$ ), and medium chain triglyceride supplements are recommended ${ }^{1-2}$ Symptoms in this case dictated more severe dietary fat restriction. The recurrence of symptoms after an increase in refined carbohydrate intake without change in fat intake suggested the need for specific restriction of this form of carbohydrate. Treatment at the time of writing is therefore based on a diet that limits long chain triglycerides to about $1.5 \mathrm{~g} / \mathrm{kg}$ in 24 hours and eliminates refined carbohydrate without restricting total calories. Medium chain triglyceride oil is used for cooking as a caloric supplement, but has not affected the plasma lipid profile.

\section{References}

I Nikkila EA. Familial lipoprotein lipase deficiency and related disorders of chylomicron metabolism. In: Stanbury JB. Wyngaarden JB. Frederickson DS. Goldstein JL, and Brown MS, eds. The metabolic basis of inherited disease. 5th ed. New York: McGraw-Hill; 1983;622-42.

2 Kwiterovich PO, Farah JR, Brown WV, Bachorik PS, Baylin SB, Neill CA. The clinical, biochemical and familial presentation of type $\mathrm{V}$ hyperlipoproteinemia in childhood. Pediatrics 1977:59:513-25.

3 Yeshuran D, Chung H, Gotto AM, Taunton AD. Primary type $\mathrm{V}$ hypcrlipoprotein in childhood. JAMA 1977:238:2518-20.

4 Deckelbaum RJ, Dupont C, LeTarte J, Pencharz P. Primary type V hypertriglyceridemia in childhood. Am J Dis Child 1983:137:396-8.

5 Fallat RW, Glucck CJ. Familial and acquired type V hyperlipoproteincmia. Atherosclerosis 1976;23:41-62.

' Greenberg BH, Blackwelder WC, Levy RI. Primary type V hyperlipoproteinemia: a descriptive study of 32 families. Ann Intern Med 1977:87:526-34

7 Boberg J, Augustin J, Baginsky ML. Quantitative determination of hepatic and lipoprotein lipase activities from human postheparin plasma. J Lipid Res 1977:18:544-7.

Correspondence to Dr G N Thompson. Division of Inherited Metabolic Discases, Clinical Research Centre, Watford Rd, Harrow HAl 3UJ, England.

Received 19 January 1987 